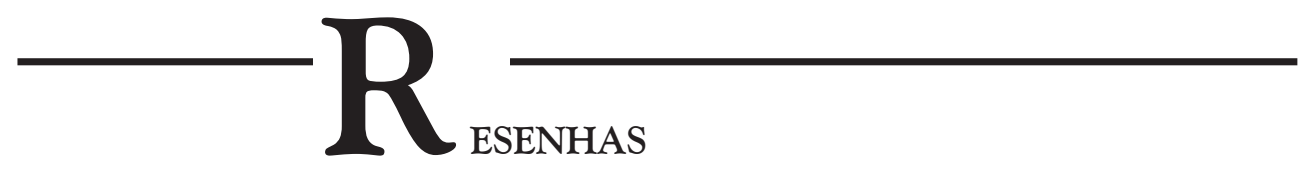

SERBIN, P. (2008), Padres, celibato e conflito social - uma história da Igreja Católica no Brasil..Tradução Laura Teixeira Motta. São Paulo: Companhia das Letras,, 446pp.

\title{
O PAPEL SOCIAL DOS SEMINARISTAS E DO CLERO NA MODERNIZAÇÃO da Igreja Católica E do PAÍs
}

\section{Silvia Fernandes}

Escrever a história sócio-cultural do clero no Brasil não é uma tarefa fácil já que os padres são atores que se inserem no cenário nacional de modo multidimensional; abarcando as esferas da cultura, da política, da vida econômica e da religião. A obra de Serbin que aqui apresentamos é, portanto, um trabalho de fôlego, "resultado de quase vinte anos de pesquisa e reflexões sobre a história da Igreja brasileira e sua atuação social e política" (:13), obtido por meio de mais de 170 entrevistas realizadas no período de 1986 a 2002, além da extensa pesquisa documental que convém a todo bom historiador.

Um dos méritos do livro é a apresentação dos padres como pessoas, com suas contradições e tensões; dilemas e realizações, inseridos numa instituição tal como a Igreja Católica, formatada por não menos ambigüidades e antíteses. Talvez por isso, o autor tenha escolhido conjugar ao relato histórico a análise sobre a presença da "psicologia da libertação", introduzindo o livro com uma 
densa descrição sobre o "significado do sacerdócio". Serbin revela ao leitor suas motivações para essa pesquisa e sua experiência religiosa e política. Fica clara sua simpatia pela igreja progressista e, várias vezes, ao longo do texto, ele expressa sugestões e posicionamentos que um leitor mais rigoroso tenderá a não simpatizar levando em conta o debate infindável sobre a isenção, compromisso que historiadores e cientistas sociais devem esmerar-se em garantir.

Serbin quer assegurar em seu texto a revelação da inter-relação entre "a oposição clerical ao regime militar, a busca da justiça social e a crise do sacerdócio" (:187) A articulação dessa tríade vai se impondo no decorrer do trabalho através da análise das relações Igreja e Estado e na percepção dos conflitos intra-eclesiais, nem sempre solvidos numa perspectiva favorável aos que se encontram na base da pirâmide hierárquica, nesse caso, os padres e seminaristas.

O livro está dividido em sete capítulos que tratam da presença dos padres na sociedade brasileira desde o século XIX até a contemporaneidade. $\mathrm{O}$ autor argumenta que padrões do catolicismo brasileiro encontrados no tempo da colônia e do Império persistiram no século XX. Esmiuça-se o papel dos jesuítas não apenas na conhecida história colonizadora, mas ainda na formação de padres diocesanos. Serbin inicia o capítulo dois analisando o que significa ser padre no Brasil. Embora a Igreja venha experimentando mais agudamente o questionamento sobre a conduta dos padres desde os anos 1960, os conflitos contemporâneos envolvendo o celibato ou ainda aqueles relacionados à população indígena tiveram precedentes no período de 1500 a 1840. A invisibilidade dos padres diocesanos; os diferentes papéis assumidos pelo clero regular (ordens religiosas) e clero secular (dioceses); as articulações entre os padres e o governo no período colonial; a relação entre Igreja e escravatura são alguns dos fatos históricos descritos neste capítulo. $\mathrm{O}$ autor dialoga com uma literatura de teólogos e estrangeiros que leram o Brasil colonial, como por exemplo, Stuart Schwartz; fato que imprime em seu relato uma análise marcadamente descritiva.

O processo conhecido como romanização, caracterizado pelo esforço da Igreja em se afirmar diante das transformações da modernidade é analisado pelo autor no terceiro capítulo, cujo recorte histórico é bastante amplo, abrangendo o período de 1840 a 1962. Aqui se afirma que "o padre do século XX baseavase em um modelo do século XVI: Trento” (:81). A partir de então, Serbin analisa a dualidade da modernização da Igreja, as mudanças dos seminários e a consolidação de uma relação entre fiéis e clero que colocavam os primeiros numa posição de dependência dos segundos. No período imperial coexistia o clero que privilegiava os sacramentos e as irmandades que contribuíram enormemente para a difusão da devoção aos santos. Os conflitos entre a Igreja e o regime imperial são analisados cuidadosamente. $\bigcirc$ governo decidia quais seminaristas estudariam na Europa e, por meio do Decreto no 839 (1851), 
intervinha até mesmo na ordenação de padres. Exemplos como a suspensão dos pagamentos aos professores dos seminários pelo governo, motivada pela reação dos bispos às intervenções, revelam as tensões entre Igreja e governo imperial. É também nesse capítulo que o leitor tem acesso a um minucioso relato da chegada da Ordem de São Vicente de Paulo ao Brasil. Os conhecidos vicentinos travaram boas relações com D. Pedro II e objetivaram não só apoiar a ordem social, como realizar uma reforma religiosa e clerical que implicava, inclusive, no afastamento dos padres da política. A igreja romanizada desse período deu ênfase às missões, ação constitutiva do catolicismo e que assume novas roupagens a cada período histórico. Ao depararmo-nos com o texto de Serbin a esse respeito fica evidente que a Igreja Católica reformula as chamadas missões de tempos em tempos. Basta olhar a "nova" edição do tema trabalhado na última Conferência Episcopal Latino Americana (CELAM) que trouxe o papa Bento XVI ao Brasil em 2007: "Discípulos e missionários de Jesus Cristo para que nossos povos Nele tenham vida". Presentes desde sempre nas estratégias evangelizadoras do catolicismo e na vida religiosa do Brasil, no século XX as missões tornaram-se um elemento fundamental para a sobrevivência institucional.

A romanização incrementa também a Grande disciplina e as reformas feitas nos seminários católicos. Ao descrever o regime disciplinar dos seminários diocesanos sob o controle dos vicentinos, Serbin destaca que estes eram similares aos mosteiros de ordens religiosas, graças à regulação do tempo, a ascese e a obediência.

No período de 1880 até 1960 foram fundados no Brasil duzentos e vinte e um seminários, representando uma média de aproximadamente três seminários ao ano. Serbin apresenta algumas tabelas que demonstram não somente a fundação de seminários, mas as séries históricas sobre o crescimento ou involução do contingente clerical. Figuras de destaque na política brasileira chegaram a passar pelos seminários diocesanos, tais como Juscelino Kubitschek e Roberto Campos, e as desistências não eram poucas.

O regime disciplinar dos seminários no período de 1900 a 1955 fez com que os padres considerassem a Igreja uma instituição perfeita. Serbin descreve detalhadamente os modos como a disciplina se aplicava nos seminários diocesanos; a rigidez no afastamento dos jovens dos amigos e da família, o controle das saídas, o baixo acesso às notícias. Enfim, os seminaristas experimentavam a separação entre Igreja e mundo e "a ruptura dos seminários com a sociedade civil isolou-os das tendências culturais gerais" (:123).

As tensões da implantação do modelo europeu de formação sacerdotal no país, o celibato e os escândalos no campo da sexualidade, bem como a visão da Igreja Católica sobre as mulheres são analisados no capítulo quatro. Serbin aposta na existência de um nacionalismo que se manifesta nas insurreições que surgiam em diferentes ordens e seminários no país contra a imposição de hábitos 
europeus. Muitos bispos apoiaram o integralismo em 1930, mas em 1950 ainda se viam costumes e disciplinas francófilos.

O autor exalta a figura de D. Hélder Câmara como "excepcional” (:142) e afirma que ele manteve a castidade durante toda a vida sacerdotal. Afirmações com tal grau de contundência colocam o leitor em busca de fontes ou citações que possam confirmar a assertiva do autor, mas elas não estão presentes no texto. Para Serbin o objetivo da romanização de manter o clero celibatário não se concretizou integralmente, e tanto os casos de pedofilia em seminários como o de Mariana (MG), na década de 1940, como os famosos afastamentos dos padres que cometiam algum tipo de desvio de caráter sexual, são tratados pelo autor. A não punição encorajava o comportamento desviante, além de favorecer o esmorecimento de certo modelo de santidade que a Igreja gostaria de imprimir em seus sacerdotes. Se a punição não vinha para os padres, o mesmo não ocorria com os seminaristas que incorressem em alguma transgressão sexual, e este fato é destacado pelo autor como "o mais rematado exemplo de disfunção disciplinar" $(: 150)$.

As tentativas na construção de um novo modelo de sacerdócio inspirado nas mudanças promovidas pelo Concílio Vaticano II (1962-1965) são analisadas no capítulo cinco, considerando o período que compreende os anos de 1945-75. Nesse período, que contempla também a emergência da Teologia da Libertação, observava-se a crítica de dentro dos seminários ao modelo de Igreja até então implantado. O movimento dos seminaristas contra o sistema tridentino foi motivado pelas transformações que aconteciam em todo o mundo no Pós-Segunda Guerra Mundial. O aparecimento de novas tecnologias e a tendência própolítica que se observava no mundo produziu os elementos necessários ao idealismo dos seminaristas desse período. Serbin faz uma extensa análise sobre o papel preponderante do seminário de Viamão (Porto Alegre) na crítica ao conservadorismo de Trento e na vitalidade intelectual que emerge impulsionada por D. Vicente Scherer, que enviava estudantes para a Universidade Gregoriana em Roma. A vitalidade cultural e a vibração dos seminaristas produziram numerosas atividades extracurriculares tais como teatro, poesia e debates literários. Os estudantes contavam com professores progressistas e dentre eles, o padre Hugo Assman, também conselheiro da Juventude Universitária Católica, a famosa JUC.

Nesse capítulo observam-se as influências exercidas por figuras conhecidas no cenário eclesial no processo de modernização da Igreja Católica. D. Paulo Evaristo Arns, D. Ivo Lorscheiter, D. Aloísio Lorcsheiter são nomes destacados por Serbin como importantes interlocutores com o Estado brasileiro no movimento pelos direitos humanos.

No turbilhão de mudanças que chegava na esteira do Concílio Vaticano II, o celibato volta a ser contestado pelos seminaristas. $\mathrm{O}$ autor ao longo de todo o livro afirma a existência da infidelidade ao voto de castidade por parte dos 
padres. Nesse capítulo ele cita pesquisas feitas na década de 1960 com dados que revelam a existência do não cumprimento do celibato por alto índice de sacerdotes. Seminaristas que viviam em pequenas comunidades, que abandonavam a batina, que estudavam ciências sociais e mantinham amizades com mulheres perturbavam a ordem disciplinar e incomodavam os superiores. No seminário de Mariana, gerido pelos vicentinos, muitos estudantes ligados à Ação Católica reivindicavam participação na gestão do seminário. Serbin relata a existência de um clima de angústia, problemas de ordem psicológica e material (falta de biblioteca atualizada, acomodações precárias) e um clericalismo radical que os seminaristas tentavam combater. Nesse caso, lograram êxito, e os vicentinos levaram em conta suas reivindicações.

A psicanálise entra em cena no livro de Serbin mais explicitamente a partir do capítulo seis. $O$ autor analisa que embora a psicologia da libertação não tenha tido a mesma repercussão da Teologia da Libertação na Igreja latinoamericana, conseguiu produzir uma grande transformação no clero brasileiro. Outras terapias psicológicas ganham legitimidade na formação do clero, mas esse movimento produz também novas crises e evasão dos padres. Havia, portanto, proibições de Roma às pesquisas psicológicas, e em 1950, o clérigo e psicanalista francês Marc Oraison foi impedido de lecionar em seminários e de publicar seus estudos. O concílio Vaticano II permitiu o uso da psicologia na formação clerical, mas a psicanálise fica praticamente fora do debate. As experiências em Cuernavaca, no México, são relatadas em detalhes e o autor traz à luz algumas interpretações psíquicas para a vocação religiosa. Empreendimento ousado que, embora mereça valorização, exigiria uma abordagem mais densa, preferencialmente numa interlocução maior com especialistas desse campo de conhecimento. Não obstante, Serbin ao relatar a ação do Pe. Géza Kösevecses, um jesuíta húngaro que se tornou psicoterapeuta, dá destaque aos efeitos de seu trabalho nos seminários: explosão sexual, conflitos com autoridade e problemas com a religião.

A situação específica dos seminários em Recife no período de D. Helder Câmara, as tensões com o Vaticano e as inovações do clero progressista são analisadas no capítulo sete. Para Serbin, os experimentos no Recife significaram uma ruptura com o regime disciplinar e um acento da descentralização.

No epílogo o autor retrata de forma fiel os temas abordados no decorrer do livro e acrescenta informações de pesquisas mais atuais sobre a questão do celibato e da psicologização do clero. Cabe uma pequena correção ao citar a última pesquisa do CERIS (:306) onde Serbin menciona os números sobre "relações com mulheres em algum momento de seu sacerdócio". Na verdade a pesquisa do CERIS perguntou sobre "envolvimento afetivo com mulheres" e embora o autor se ressinta por não ter sido abordado no questionário questões de caráter psicológico, a publicação da pesquisa contemplou uma análise sob essa perspectiva feita pelo psicanalista Joel Birman. 
Para quem deseja adentrar no universo da cultura católica brasileira e seus agentes reprodutores, o livro de Serbin se coloca como uma ótima oportunidade e abre novas frentes de pesquisa interdisciplinares.

\section{Notas}

1 MEDEIROS, K. \& FERNANDES, S.R.A. (orgs.) (2005) O padre no Brasil - interpelações, dilemas e esperanças. São Paulo: Loyola.

Silvia Alves Fernandes (silvfernandes@terra.com.br) Professora Adjunta da Universidade Federal Rural do Rio de Janeiro - UFRRJ/ Instituto Multidisciplinar. 